\title{
Development of character strengths across the deployment cycle among U.S. Army soldiers
}

\author{
William J. Chopik ${ }^{1}$ \\ Whitney L. Kelley ${ }^{2,3}$ \\ Loryana L. Vie ${ }^{2,3}$ \\ Jeewon $\mathrm{Oh}^{1}$ \\ Douglas G. Bonett ${ }^{4}$ \\ Richard E. Lucas ${ }^{1}$ \\ Martin E. P. Seligman ${ }^{2}$ \\ ${ }^{1}$ Michigan State University \\ ${ }^{2}$ University of Pennsylvania \\ ${ }^{3}$ Research Facilitation Laboratory \\ ${ }^{4}$ University of California, Santa Cruz
}

Word Count: 4954

Author Note

Correspondence concerning this manuscript should be addressed to William J. Chopik, Department of Psychology, Michigan State University, 316 Physics Rd., East Lansing, Michigan 48824. E-mail: chopikwi@msu.edu

We acknowledge the significant support provided to this project by the men and women of the Office of the Deputy Under Secretary of the Army, the Army Analytics Group, and the Research Facilitation Laboratory. We also thank Dr. Les McFarling and Captain Kristin Saboe, PhD from the Army Resiliency Directorate, for assisting us with acquiring GAT data. This paper is dedicated in memory of Christopher Peterson. 


\begin{abstract}
Objective: Despite a narrative of post-traumatic growth and resilience, research reliably demonstrating positive character development following adversity has proved elusive. In the current study, we examined changes in character strengths in Army soldiers deploying for the first time.
\end{abstract}

Method: The sample was comprised of 212,386 Army soldiers $\left(M_{\text {age }}=26.5\right.$ years old, $\mathrm{SD}=$ 7.13; 70.8\% White) who were deploying for the first time. Character strengths were assessed once before and up to three times following soldiers' return from deployment.

Results: We found evidence for two classes of change — a resilient class ("stable high") and a declining class (“persistent low”). Most soldiers were resilient — they had high levels of character strengths prior to deployment and changed very little across the deployment cycle. Approximately $40 \%$ of soldiers started with lower character and experienced initial declines post-deployment, from which they experienced no more than small gains over time.

Conclusions: Character strengths were highly stable across the deployment transition but some soldiers experienced initial declines from which they never fully rebounded. The findings are discussed in the context of the mechanisms that drive character development.

Keywords: character strengths, growth mixture modeling, U.S. Army soldiers, resilience, character development 


\section{Development of character strengths across the deployment cycle among U.S. Army soldiers}

Can exposure to adversity lead to positive outcomes or even personal growth? Despite the persistent narrative of post-traumatic growth and resilience, research that reliably demonstrates positive character development following adversity has proved elusive (Jayawickreme \& Blackie, 2014). Chief among the reasons for this inconsistent evidence is a lack of prospective longitudinal data on a large group of individuals undergoing a common source of potential adversity. One such adversity could be the deployment of armed service members (Bonanno et al., 2012). Deploying involves a great deal of stress; service members often leave behind vital support sources, suspend their lives, and encounter frequent stressors. But does the deployment experience facilitate character development over time? In the current study, we tested this question by examining changes in character strengths among over 200,000 Army active duty, Reserve, and National Guard soldiers.

\section{Post-traumatic growth and resilience}

The term resilience has been used to characterize several phenomena, including good outcomes despite high-risk status, sustained integrity under threat, and recovery from trauma (Masten et al., 1990). Additionally, many different theoretical models for characterizing resilience (and even growth) have been developed (Jayawickreme \& Blackie, 2016a, 2016b; Luthar, 2006). Many of these models suggest that, in order to flourish following adversity, individuals must reframe adversity, develop a narrative around the adversity, and engage in critical self-reflection, with the hope that these steps (and others) will lead to future resilience and better emotion regulation (Tedeschi \& McNally, 2011). For consistency with the posttraumatic growth and adult resilience literature, the present study operationalizes resilience as stable higher levels of character strengths and the the absence of negative outcomes or declines 
during or following potentially harmful circumstances; this operationalization closely mirrors others in the literature, particularly those pertaining to how well-being and psychological adjustment change following adversity (Infurna \& Luthar, 2016c). ${ }^{1}$

What we do know about growth of positive characteristics in soldiers often comes from research in which soldiers are asked about their responses and experiences after the fact (e.g., Feder et al., 2008). In one exception, Bonanno et al. (2012) found that the majority of soldiers (>83\%) follow a resilient trajectory in which they had few PTSD symptoms prior to deployment and few PTSD symptoms 3- and 6-years post-deployment. In this same study, there was also a reliable number of soldiers (e.g., $~ 8-9 \%$ ) who declined in PTSD symptoms over the same pre- to post-deployment interval. Such high rates of resilience and positive change are common in studies examining adjustment in response to life events in samples of military personnel, those recovering from traumatic brain injuries or life threatening illnesses, individuals experiencing bereavement, and individuals experiencing a variety of other adverse life events (see GalatzerLevy et al., 2018; Infurna \& Luthar, 2018; Lam et al., 2010; Porter et al., 2017).

\section{Post-traumatic growth and resilience as positive personality change}

Growth and resilience in the context of personality and character strengths. Despite

the fact that the concept of post-traumatic growth focuses on positive characteristics, these positive characteristics (e.g., character strengths) are rarely the focus of prospective longitudinal studies involving potentially stressful events. In addition, when positive characteristics are the focus, they are limited to general evaluations of an individual's life overall (e.g., subjective wellbeing), rather than more trait-like, individual difference constructs. In Jayawickreme and Blackie

\footnotetext{
1 We acknowledge, however, that this definition of resilience does not contain the hallmark of "bouncing back" following an initial decrease in standing on a psychological characteristic after a potentially adverse event (Infurna \& Jayawickreme, 2019).
} 
(2014)'s conceptualization of post-traumatic growth as positive personality change, they leveraged the existing post-traumatic growth literature in the context of personality change processes. Specifically, they note a number of places in which growth and resilience are framed in terms of how an individuals' characteristic patterns of thoughts, feelings, and behavior (i.e., their personalities) change in response to non-normative life events (Tennen \& Affleck, 1998, 2009). Such thinking is most clearly seen in studies and methods assessing prospective changes in characteristics that have trait-like features (e.g., life satisfaction), albeit characteristics that are not traditionally considered as personality traits by most people (Lucas, 2005, 2007). Although some previous work posits that personality change following stressful events can inform research on growth and resilience, concerted efforts to study such changes in personality and character strengths have lagged behind research on indicators of general adjustment (Infurna \& Jayawickreme, 2019; Jayawickreme \& Blackie, 2014, 2016a). However, given that resilience, functioning, and interpersonal behavior are all at least partially attributable to individual differences in personality and character strengths, there have been direct calls to integrate the study of positive personality traits into the study of growth and resilience (Infurna \& Jayawickreme, 2019; Letzring et al., 2005; Riolli et al., 2002). Such an approach would move the field closer to a multidimensional understanding of how challenging life experiences can transform an individual with respect to their adjustment, daily behavior, enduring personality traits, and the stories they tell about their lives (Frazier et al., 2009; Infurna \& Jayawickreme, 2019; Jayawickreme \& Blackie, 2014; Jayawickreme \& Zachry, 2018; McLean \& Syed, 2016; Yanez et al., 2011). To date though, there is a relative ignorance over whether personality and character strengths, often considered to be relevant in the growth and resilience literature, show similar changes following adversity as more traditional indicators of adjustment. To adequately 
investigate post-traumatic growth and resilience, it would seem necessary to investigate a set of characteristics (e.g., strengths) that may change following challenging circumstances.

The Values in Action inventory of character strengths. One important taxonomy of positive characteristics is Peterson and Seligman (2004)'s conceptualization of strengths and virtues within the Values in Action Inventory of Strengths. The inventory of strengths includes 24 positive characteristics on which individuals can vary (e.g., creativity, kindness, hope, gratitude, leadership). These character strengths are considered to be enduring individual differences characteristics with a moderate degree of stability over time and across the lifespan (Disabato et al., 2017). Although longitudinal data on character strengths are relatively rare, there is an implicit assumption in the field that character strengths are at least somewhat malleable and changeable. Studies of cross-sectional age differences suggest that normative changes may be possible, although it is unclear from where these changes might originate (Chopik et al., 2018; Martínez-Martí \& Ruch, 2014). There is also some evidence that character strengths vary considerably across different cultures, subpopulations, and settings, suggesting that there may be at least some contextual influences on the development of character strengths (McGrath, 2015; Park \& Peterson, 2010; Park et al., 2006).

In the current study, we propose that the deployment experience might constitute an experience that might alter the normative development of character strengths. This proposal comes from work suggesting that, although people vary in their evaluations of the experience, deployment experiences are generally seen as stressful and combat exposure is one of the most consistent predictors of post-deployment adjustment in psychological characteristics (Brewin et al., 2000; Foy et al., 1984; Hoge et al., 2006; Hoge et al., 2004; Smith et al., 2008). For some soldiers, the deployment experience can be a high-magnitude stressor. For other soldiers, the 
deployment experience can reflect more of a low-level, chronic stressor that lasts the length of their deployment. Either way, we suggest that, on average, the experience constitutes a significant enough experience that it might drive character development. It is the case that, among all soldiers who deployed, they are spending significant amounts of time away from their families and sources of support—often in unfamiliar places that have the potential for danger. Indeed, work comparing cross-sectional samples assessed before and after an adverse event provides some indication that character development following adversity is possible (Lamade et al., 2019; Martínez-Martí \& Ruch, 2017; Schueller et al., 2015; Shoshani \& Slone, 2016).

Although character strengths have not been the direct focus of studies examining psychological change following adversity, the existing work on personality development following life events and adverse circumstances provides some precedent to expect that there may be individual differences in adaptation to the deployment experience (Bleidorn et al., 2016; Jayawickreme \& Blackie, 2014; Jayawickreme et al., 2016). Given evidence identifying character strengths as antecedents of health behavior, subjective well-being, and physical health, modeling whether or not the deployment experience is associated with different trajectories of character is a worthwhile endeavor (Proyer et al., 2013)

One difficulty that emerges in providing an assessment of the field of character development to date is that the taxonomy necessarily contains many strengths. Several data reduction efforts (i.e., factor analyses) have been undertaken since the measure's inception (e.g., McGrath, 2014; Shryack et al., 2010). Measures have also been refined over time, resulting in an abbreviated 24-item measure of character strengths (e.g., the Abbreviated Character Strengths Test (ACST); Peterson et al., 2011). In one study among civilians (Vanhove et al., 2016), researchers found support for a modified six-factor solution that closely resembled the thematic 
organization by Peterson and Seligman (i.e., wisdom/knowledge, courage, humanity, justice, temperance, transcendence). In another study among U.S. soldiers (from the same data source used in the current study), Vie and colleagues (2016) found a four-factor solution for character strengths (intellect, civic strengths, temperance, and warmth). Specifically, intellect is comprised of the character strengths of creativity, curiosity, critical thinking/open-mindedness/good judgement, love of learning, and perspective/wisdom. Civic strengths are comprised of the character strengths of honesty, teamwork, fairness, and leadership. Warmth is comprised of the character strengths of love/closeness with others, kindness/generosity, gratitude/thankfulness, hope/optimism, and playfulness/humor. Temperance is comprised of the character strengths of forgiveness/mercy, modesty/humility, prudence/caution, and self-control. Based on these measurement efforts, we will be examining changes in these four broader character strength dimensions in the current study as these validation efforts were made among U.S. soldiers.

\section{The Current Study}

We examined how soldiers' character strengths change from before deployment to across three follow-up assessments approximately one year apart following deployment. We also adopted Infurna and Luthar (2016c)'s approach to modeling changes in character by allowing variability in soldiers' starting levels and changes in character strengths to be freely estimated, as opposed to requiring zero variability or equality of variability across classes of soldiers (see Model Testing Strategy below). Because the current study was entirely exploratory and descriptive with respect to the number of classes and trajectories of character development, we made no formal hypotheses or predictions about these patterns.

\section{Method}

\section{Sample Selection Procedures}


We had access to a population of 212,386 Army soldiers (including active duty, Reserve, and National Guard) who met the following criteria: 1) earliest deployment record was between 5/7/2009 and 11/29/2016, 2) completed at least one Global Assessment Tool (GAT; see below) survey before 9/30/2017 and within a year of their deployment (before or after), and 3) indicated through an electronic "opt-in" procedure that their responses could be used for research purposes. Up to two additional post-deployment GAT surveys (9-15 months following the preceding GAT and prior to a subsequent deployment) were included, when available. Figure 1 shows the GAT completion patterns in this study. Over 11,000 participants completed qualifying GAT surveys at all 4 time points. The sample size at each time point was as follows: PreDeployment GAT: 126,357 soldiers (40.5\% missing); Post-Deployment GAT \#1: 149,941 soldiers (29.4\% missing); Post-Deployment GAT \#2: 56,957 soldiers (73.2\% missing); and PostDeployment GAT \#3: 22,750 soldiers (89.3\% missing). The University of Pennsylvania Institutional Review Board and a Department of Defense Human Research Protection Official approved this study.

\section{Measures}

Character. Character was assessed on the GAT, a psychosocial survey that soldiers complete annually. Soldiers completed the 24-item ACST, which was adapted from the Values in Action Inventory of Strengths (VIA-IS; Peterson et al., 2011; Peterson \& Seligman, 2004). Soldiers were asked to respond to the character strength questions based on their behaviors in the preceding four weeks. Items were presented on an 11-point response scale ranging from 0 (never) to 10 (always) and recoded to range from 0 to 5 for the present analyses. Based on initial validation of the GAT character measure (Vie et al., 2016), and the loss of two items from the warmth subscale during a subsequent revision to the GAT (i.e., "love or closeness with others 
(friends, family members)" and "hope or optimism"), we included 16 character items in this study to maintain a consistent set of items over time. Across the deployment cycle, we examined overall character $(\alpha=.94-.96)$, as well as four character subscales: intellect (5 items, $\alpha=.88$ .92 ), civic strengths (4 items, $\alpha=.86-.89$ ), warmth (3 items, $\alpha=.80-.86$ ), and temperance (4 items, $\alpha=.84-.87)$.

Demographic and Military Characteristics. Demographic characteristics (age, sex, education, race/ethnicity, branch, component, and rank), obtained from Defense Manpower Data Center (DMDC) Master Personnel Files, were assessed near the beginning of each soldier's deployment. Deployment dates were obtained from the DMDC Contingency Tracking System Deployment File.

\section{Model Testing Strategy}

Models were run in MPlus Version 7.11 (Muthén \& Muthén, 1998-2012). Descriptive analyses were performed using SAS software (version 9.4), and 95\% confidence intervals surrounding the latent class estimated means were calculated in $\mathrm{R}$ version 3.4.2. All analyses were performed within the Person-Event Data Environment (PDE), a secure virtual Army data repository and analysis environment (Vie et al., 2013; Vie et al., 2015). This study adheres to the guidelines for reporting on latent trajectory studies (van de Schoot et al., 2017).

We used growth mixture modeling (GMM), which combines latent growth curve modeling and mixture modeling to determine latent classes. We modeled the intercept at predeployment, with a slope reflecting differences between pre-deployment and post-deployment (average), and a second slope reflecting character changes across the three post-deployment assessments. Because the first slope comprised only two time points, we were limited to testing a linear slope. For the second slope, which was based on three time points, we allowed the middle 
time point to be freely estimated in order to assess the degree of nonlinearity. Allowing the middle time point to be freely estimated also provided the ability to accommodate a quadratic trajectory of change, if needed. Because variation in growth factors may differ across classes, we did not constrain the residual variances across classes to be equal. We modeled the present analyses after Infurna and Luthar (2016c)'s Model 3; however, there are a few model differences worth noting.

First, we did not have sufficient time points to estimate changes in character across multiple time points prior to deployment. Instead, our pre-deployment slope assessed differences between pre-deployment character and the average post-deployment character. Second, because of variation in the timing that GAT surveys were completed during each GAT window, we included control variables that accounted for the timing of each GAT. These control variables were modeled within time and within class, and each time variable was included as a predictor of the character indicator at that time point only. For example, the control variable for how many days between the pre-deployment character assessment and actual deployment was only included as a predictor of the pre-deployment character indicator. Because the objective was to measure how character changes across the deployment cycle, no other covariates were included in these models. Models specified 100 initial stage starts and 50 final stage optimizations. Missing data in this study were assumed to be missing at random. We used maximum likelihood estimation with robust standard errors in Mplus to account for missing data. We considered AIC, BIC, and Bootstrapped Likelihood Ratio Tests (BLRT), along with the consistency across classes, and interpretability of the classes, for model selection (Frankfurt et al., 2016; Jung \& Wickrama, 2007; Ram \& Grimm, 2009; Smith \& Ehlers, 2020). We also report the relative entropy for each model, as a measure of how well individuals are classified in each model. Entropy levels 
approaching 1 indicate appropriate model selection (Jung \& Wickrama, 2007).

\section{Results}

On average, soldiers in the sample were 26.5 years old (SD: 7.1), non-Hispanic White (70.8\%), male (86.3\%), and had a high-school level education or less (73.1\%). Most soldiers were enlisted (86.7\%) and were active duty (67.9\%), as opposed to Reserve (10.8\%) or National Guard (21.3\%). Deployments averaged 255 days (SD: 91.3). On average, the pre-deployment GAT was taken 5.9 months (SD: 3.4) prior to deployment, and the first post-deployment GAT was taken 5.6 months (SD: 3.5) after the end of deployment. The second and third postdeployment GATs were taken approximately one year after the preceding GAT (12.4 months [SD: 1.2] and 12.4 months [SD: 1.1], respectively). As expected, retest correlations of character responses were more highly correlated within the post-deployment window $(r=.44-.55)$, compared to across the deployment transition (i.e., associations between pre- and postdeployment character; $r=.35-.46)$. The average correlation between character subscales within time points was high $(r=.65-.81)$.

\section{Model Selection}

The majority of studies suggesting relatively high percentages of people who are resilient or grow in response to life events use variations in growth mixture modeling to identify subgroups of individuals who vary in their initial psychological characteristics and how they change over time (Bonanno, 2005). However, many of these studies have often made the statistical assumptions that there is no variability at people's initial standing on a construct, no variability in growth trajectories in that construct, and no subgroups that can have different initial or growth trajectory patterns. Relaxing one or more of these assumptions has been shown to affect estimates of resilience and posttraumatic growth (oftentimes reducing the prevalence of 
resilience and growth; Infurna \& Grimm, 2017; Infurna \& Luthar, 2016a, 2016b, 2016c, 2017; Infurna et al., 2015; Infurna et al., 2017). However, imposing such constraints makes little sense - soldiers likely vary in their characteristics before they deploy and change in different ways over time. In the current study, we relaxed the assumptions of no variability at the initial time point, no variability in growth trajectories, and no subclasses to more appropriately estimate how soldiers' character strengths change across the deployment cycle.

For the growth curve component, we initially took a latent growth mixture modeling (LGMM) approach and allowed the intercept and the two growth parameters (pre- vs. average post-deployment, and post-deployment change) to be random. We found, however, that the variances of the two growth parameters were small and near zero, so we constrained the variances and covariances of the two random growth parameters to be zero. Thus, we felt justified in making this assumption for the model based on features for how individuals were actually changing over time.

We tested whether introducing additional classes significantly improved fit to the data. Ultimately, we settled on a two-class solution. One group was considered a resilient "stable high" class and the other group was considered a declining "persistent low" class (see below for exact patterns of change). AIC and BIC improved substantially between the one and two class solution, and the BLRT consistently indicated that the 2-class model fit the data significantly better $(p<.0001)$ than the 1 -class model (Table 1). However, convergence failure for several of the character measures with a 3-class model made comparisons between the two and three class solutions difficult. For the overall character measure, soldiers assigned to the stable high class had a .87 average predicted probability of belonging to the stable high class. Similarly, soldiers assigned to the persistent low class had a .83 average predicted probability of belonging in the 
persistent low class. The average predicted probabilities for the four character subscales were fairly similar (Stable high: .79-.84; Persistent low: .86-.89). We also observed a high degree of consistency in how the soldiers were classified across the five character strengths: $59.23 \%$ of soldiers were classified as "stable high" in at least four models, and $22.64 \%$ of soldiers were classified as "persistent low" in at least four models. ${ }^{2}$ Additionally, the two-class solution produced two highly interpretable classes. The 2-class model was also independently replicated when reproducing the models in two random halves of the sample (see Supplementary Materials). For these reasons, we retained the two-class solution.

Worth noting, we refer to these classes as "high" and "low" not as a means of characterizing absolute levels of character; it is not the case that one group has character and the other does not. Rather, these labels are meant characterize the two classes in relation to one another (i.e., one class had participants reporting higher character than another). Thus, it is not the case that, on average, the persistent low character class is absolutely low on overall character, intellectual strengths, civic strengths, warmth, and temperance; they are just lower than the stable high group.

The two-class solution revealed a resilient "stable high" group and a declining "persistent low" group (Figure 2). Beginning with overall character, the stable high group comprised $63 \%$ of the sample. Soldiers in this group reported relatively high character prior to deployment, maintained high character following deployment, and demonstrated slight growth and/or stability in character following deployment. The persistent low group comprised $37 \%$ of the sample.

\footnotetext{
${ }^{2}$ Specifically, $6.52 \%$ of soldiers were never classified as being part of the "stable high" group across the five character strength outcomes, whereas $16.12 \%$ (one time), $7.53 \%$ (two times), $10.59 \%$ (three times), $26.67 \%$ (four times), and $32.57 \%$ (five times) of soldiers were classified as "stable high" at least once. Being stably high in one character strength over time was associated with being stably high in another character strength over time.
} 
Compared to soldiers in the stable high group, soldiers in the persistent low group reported lower character prior to deployment. Following deployment, soldiers in this group reported a drop in character, followed by some very minor gains toward their pre-deployment character, but ultimately this group did not recover their pre-deployment character strength levels.

We observed comparable stable high and persistent low classes across each of the four character subscales; however, the percentage of the sample classified as falling into each group did fluctuate somewhat (Table 2). Additionally, in some cases, the persistent low classes experienced more recovery depending on the specific character strength measured. But ultimately their character strengths levels did not return to pre-deployment levels. Membership in the stable high group ranged from $52 \%$ to $60 \%$ of the sample for each character subscale.

\section{Missing Data}

A comparison of soldiers with 4 GAT surveys to those with 3 or fewer revealed the two groups were fairly similar. Most notably, the group with all 4 GAT surveys was slightly older (28.7 vs 26.5$)$, had a greater percentage of officers $(23.3 \%$ vs $12.9 \%)$, and had a greater percentage of soldiers with post-secondary education (39.9\% vs $26.9 \%)$. Additionally, the group with 4 GAT surveys had slightly higher average overall character scores at all four time points $(4.16,4.06,4.17,4.16)$, compared to the group with 3 or fewer GAT surveys $(4.11,3.99,4.06$, 4.13). The resulting two-class solution and patterns of change were consistent among those with and without the complete number of GAT assessments.

\section{Discussion}

In the current study, the majority of soldiers were resilient - they had high levels of character strengths prior to deployment and changed very little across the deployment cycle. Approximately 40-50\% of soldiers experienced initial declines in each character strength, 
followed by either stability or a slight rebound in each character strength during the postdeployment period. The current study extends previous research examining individual differences in change across the deployment cycle by prospectively examining changes in character strengths and more appropriately considering the assumptions regarding intra- and inter-individual changes in a GMM framework.

Previous research has identified the vast majority of individuals as resilient or improving in adjustment across the deployment experience, such as the near $90 \%$ of previous military samples. Unlike these studies and others focusing on broader adjustment indices (e.g., depression and subjective well-being; Infurna \& Luthar, 2016c, 2017), we found that resilience (a consistently high level of character) represented about 50-60\% of soldiers in our sample. There are many reasons why the character changes observed among soldiers in the current study might differ from previous work in other samples. For example, in the current study we focused on (a) more trait-like character strengths (instead of well-being indices), (b) how soldiers changed across the deployment transition (instead of the many other experiences [e.g., bereavement] that other studies have examined), and (c) had a large sample of participants undergoing a similar transition that often occurs as a result of an individual's choice to enlist (instead of smaller numbers of individuals responding to more stochastic events). As in previous studies, when the intercepts and slopes of character strengths are statistically allowed to vary across and within groups in growth mixture modeling, there is little evidence for dramatic growth in positive psychological characteristics (Bonanno et al., 2002; Infurna \& Luthar, 2016c; Infurna et al., 2017).

Investigating the mechanisms underlying character development in response to life events would further clarify how and why individuals change in response to adverse events (Bleidorn et 
al., 2016; Jayawickreme \& Blackie, 2014). Our current understanding of the reasons why individuals are resilient or sometimes recover from adverse experiences is mostly theoretical and specific mechanisms have not been critically investigated. For example, many of the proposed preconditions for growth and resilience involve cognitive reframing and self-reflection (Tedeschi \& McNally, 2011). Unfortunately, very few prospective studies examine these psychological processes that are hypothesized to drive growth and resilience. Without a detailed understanding of the sequence and steps through which individuals process life events, we cannot understand why and how individuals weather (or even grow from) adverse events.

There appears to be an accumulation of evidence regarding the lack of positive psychological change following adverse experiences. Future research can extend the findings of the current report and others in at least four ways. First, the particular literature on psychological change that we reviewed is often limited to how individuals adapt to adverse life circumstances (Mangelsdorf et al., 2018). However, in the broader literature examining personality change, ostensibly positive, or even neutral, life events can also cultivate change in individual characteristics (Schwaba et al., 2019). Nevertheless, the descriptive evidence supporting consistent psychological change in response to any new life events and circumstances is still too preliminary to construct specific models for the exact conditions under which individuals change (Bleidorn et al., 2016). Future research can make important steps in quantifying when and why changes in character strengths are most likely to happen.

Second, like many other studies of psychological adaption to a potentially adverse experience, we did not have fine-grained measures to assess individual soldiers' perceptions of their deployment experiences - this is a major limitation of the current work. We again acknowledge that people vary considerably in their perceptions of life events (Kelly, 1989). For 
some soldiers, the deployment experience can be a high-magnitude stressor. For other soldiers, the deployment experience can reflect more of a low-level, chronic stressor that lasts the length of their deployment. For yet others, the deployment experience can be an exciting and positive experience. But which type of experience is necessary to cultivate character development? To date, there is a relative ignorance about the exact conditions necessary to cultivate growth and resilience following a potentially adverse event (Infurna \& Jayawickreme, 2019; Jayawickreme \& Blackie, 2014; Luhmann et al., 2019). Future research can assess the wide variety of subjective evaluations of the deployment experience either as it is happening or shortly afterward to more precisely identify what types of stressors lead to growth and resilience in character, if they do at all.

Third, we assessed character strengths at approximate annual intervals following the deployment experience. Although this is appropriate for quantifying year-to-year changes in character strengths before and after the deployment experience, it could be entirely possible that character strengths might be changing on different time scales that are lost when assessing character strengths so infrequently. For example, for some stressors, psychological changes and adaptation might happen at times more proximate to an adverse event (Belcher et al., 2011). Future research and theory can provide more guidance about the exact time course over which it is appropriate to study psychological changes in response to adversity.

Finally, examining the function and consequences of character change is also important. In other words, do the changes in character strengths we observed matter for individual soldiers? One implicit assumption in studies examining adaptation to life events is that any changes observed reflect, at least in part, how individuals are adjusting to their new life circumstanceswhether soldiers are consciously engaging in efforts to adapt is still unknown. But are soldiers 
whose character strengths are resilient to the deployment cycle happier and healthier? Does recovering from an adverse event translate into a more meaningful assessment of the event (Jayawickreme \& Blackie, 2014)? Or are any differences in health and well-being between the classes attributable to the mean level differences between classes prior to deployment? Although much research is appropriately focused on quantifying whether or not change is occurring, an additional question is whether or not these changes are important for individuals' lives. Future research can examine the utility of these changes in character strengths for soldiers' health and well-being.

\section{Conclusion}

The current study was the largest investigation of character change in U.S. Army soldiers across the deployment cycle ever conducted. We found that resilience best characterized the nature of character strengths across the deployment cycle, with the majority of soldiers maintaining stable, high character strengths. A smaller proportion of soldiers experienced an initial decline in character strengths from pre- to post-deployment, followed by stability or small gains in character strengths that never quite rebounded to pre-deployment levels. The current study was an important step in describing individual differences in psychological changes experienced by soldiers across the deployment cycle. Future research can capitalize on these findings by examining the specific conditions under which psychological change is possible and the utility of these changes for soldiers' health and well-being upon returning from deployment. 


\section{Declaration of Conflicting Interests}

The U.S. Department of Defense (DOD) does not exercise any editorial, security, or other control over the information in this article. The authors assume responsibility for the veracity, accuracy, and source documentation of the material, including no use of classified material and conformity to copyright and usage permissions. The views expressed in this article are those of the authors and do not necessarily represent the official policy of the Department of the Army, the DOD, or the U.S. Government.

Dr. Seligman reported the following: 1) the University of Pennsylvania has a proprietary interest in the Master Resilience Training program, the backbone of the U.S. Army's Comprehensive Soldier Fitness program; 2) the University of Pennsylvania licenses such resilience and positive psychology training programs to private companies, and Dr. Seligman receives a nominal fee from the university for some of these; and 3) Dr. Seligman is often paid to give speeches in which he mentions resilience and resilience training. No other disclosures were reported. 


\section{Funding}

This publication stems from a military-civilian collaboration, which is supported in part by the Robert Wood Johnson Foundation through a grant to the Positive Psychology Center of the University of Pennsylvania, Martin E. P. Seligman, Principal Investigator. Research reported in this publication was also supported by a grant awarded by the Templeton Foundation's Pathways to Character Initiative. 


\section{References}

Belcher, A. J., Laurenceau, J.-P., Graber, E. C., Cohen, L. H., Dasch, K. B., \& Siegel, S. D. (2011). Daily support in couples coping with early stage breast cancer: Maintaining intimacy during adversity. Health Psychology, 30(6), 665.

Bleidorn, W., Hopwood, C. J., \& Lucas, R. E. (2016). Life events and personality trait change. Journal of Personality.

Bonanno, G. A. (2005). Resilience in the face of potential trauma. Current Directions in Psychological Science, 14(3), 135-138.

Bonanno, G. A., Mancini, A. D., Horton, J. L., Powell, T. M., LeardMann, C. A., Boyko, E. J., Wells, T. S., Hooper, T. I., Gackstetter, G. D., \& Smith, T. C. (2012). Trajectories of trauma symptoms and resilience in deployed US military service members: prospective cohort study. The British Journal of Psychiatry, 200(4), 317-323. https://doi.org/10.1192/bjp.bp.111.096552

Bonanno, G. A., Wortman, C. B., Lehman, D. R., Tweed, R. G., Haring, M., Sonnega, J., Carr, D., \& Nesse, R. M. (2002). Resilience to loss and chronic grief: a prospective study from preloss to 18-months postloss. Journal of Personality and Social Psychology, 83(5), 1150.

Brewin, C. R., Andrews, B., \& Valentine, J. D. (2000). Meta-analysis of risk factors for posttraumatic stress disorder in trauma-exposed adults. Journal of consulting and clinical psychology, 68(5), 748.

Chopik, W. J., Newton, N. J., Ryan, L. H., Kashdan, T. B., \& Jarden, A. J. (2018). Gratitude across the life span: Age differences and links to subjective well-being. Journal of Positive Psychology. 
Disabato, D. J., Kashdan, T. B., Short, J. L., \& Jarden, A. (2017). What Predicts Positive Life Events that Influence the Course of Depression? A Longitudinal Examination of Gratitude and Meaning in Life [journal article]. Cognitive therapy and research, 41(3), 444-458. https://doi.org/10.1007/s10608-016-9785-x

Feder, A., Southwick, S. M., Goetz, R. R., Wang, Y., Alonso, A., Smith, B. W., Buchholz, K. R., Waldeck, T., Ameli, R., Moore, J., Hain, R., Charney, D. S., \& Vythilingam, M. (2008). Posttraumatic growth in former Vietnam prisoners of war. Psychiatry, 71(4), 359-370. https://doi.org/10.1521/psyc.2008.71.4.359

Foy, D. W., Sipprelle, R. C., Rueger, D. B., \& Carroll, E. M. (1984). Etiology of posttraumatic stress disorder in Vietnam veterans: analysis of premilitary, military, and combat exposure influences. Journal of consulting and clinical psychology, 52(1), 79.

Frankfurt, S., Frazier, P., Syed, M., \& Jung, K. R. (2016). Using Group-Based Trajectory and Growth Mixture Modeling to Identify Classes of Change Trajectories. The Counseling Psychologist, 44(5), 622-660. https://doi.org/10.1177/0011000016658097

Frazier, P., Tennen, H., Gavian, M., Park, C., Tomich, P., \& Tashiro, T. (2009). Does selfreported posttraumatic growth reflect genuine positive change? Psychological Science, 20(7), 912-919.

Galatzer-Levy, I. R., Huang, S. H., \& Bonanno, G. A. (2018). Trajectories of resilience and dysfunction following potential trauma: A review and statistical evaluation. Clinical Psychology Review, 63, 41-55. https://doi.org/10.1016/j.cpr.2018.05.008

Hoge, C. W., Auchterlonie, J. L., \& Milliken, C. S. (2006). Mental health problems, use of mental health services, and attrition from military service after returning from deployment to Iraq or Afghanistan. JAMA, 295(9), 1023-1032. 
Hoge, C. W., Castro, C. A., Messer, S. C., McGurk, D., Cotting, D. I., \& Koffman, R. L. (2004). Combat duty in Iraq and Afghanistan, mental health problems, and barriers to care. New England journal of medicine, 351(1), 13-22.

Infurna, F. J., \& Grimm, K. J. (2017). The use of growth mixture modeling for studying resilience to major life stressors in adulthood and old age: Lessons for class size and identification and model selection. The Journals of Gerontology: Series B.

Infurna, F. J., \& Jayawickreme, E. (2019). Fixing the Growth Illusion: New Directions for Research in Resilience and Posttraumatic Growth. Current Directions in Psychological Science, 28(2), 152-158. https://doi.org/10.1177/0963721419827017

Infurna, F. J., \& Luthar, S. S. (2016a). Parents reactions to the loss of their child: Resilience is by no means typical. International Journal of Psychology, 51, 374.

Infurna, F. J., \& Luthar, S. S. (2016b). Resilience has been and will always be, but rates declared are inevitably suspect: Reply to Galatzer-Levy and Bonanno. Perspectives on Psychological Science, 11(2), 199-201.

Infurna, F. J., \& Luthar, S. S. (2016c). Resilience to major life stressors is not as common as thought. Perspectives on Psychological Science, 11(2), 175-194. https://doi.org/10.1177/1745691615621271

Infurna, F. J., \& Luthar, S. S. (2017). Parents' adjustment following the death of their child: Resilience is multidimensional and differs across outcomes examined. Journal of Research in Personality, 68, 38-53.

Infurna, F. J., \& Luthar, S. S. (2018). Re-evaluating the notion that resilience is commonplace: A review and distillation of directions for future research, practice, and policy. Clinical Psychology Review, 65, 43-56. https://doi.org/10.1016/j.cpr.2018.07.003 
Infurna, F. J., Rivers, C. T., Reich, J., \& Zautra, A. J. (2015). Childhood trauma and personal mastery: Their influence on emotional reactivity to everyday events in a community sample of middle-aged adults. PLOS ONE, 10(4), e0121840. https://doi.org/10.1371/journal.pone.0121840

Infurna, F. J., Wiest, M., Gerstorf, D., Ram, N., Schupp, J., Wagner, G. G., \& Heckhausen, J. (2017). Changes in life satisfaction when losing one's spouse: individual differences in anticipation, reaction, adaptation and longevity in the German Socio-economic Panel Study (SOEP). Ageing \& Society, 37(5), 899-934.

Jayawickreme, E., \& Blackie, L. E. R. (2014). Post - traumatic growth as positive personality change: Evidence, controversies and future directions. European Journal of Personality, 28(4), 312-331.

Jayawickreme, E., \& Blackie, L. E. R. (2016a). Exploring the Psychological Benefits of Hardship: A Critical Reassessment of Posttraumatic Growth. Springer.

Jayawickreme, E., \& Blackie, L. E. R. (2016b). Posttraumatic growth: A worthy idea poorly studied. In E. Jayawickreme \& L. E. R. Blackie (Eds.), Exploring the Psychological Benefits of Hardship (pp. 67-75). Springer International Publishing.

Jayawickreme, E., Brocato, N. W., \& Blackie, L. E. R. (2016). Wisdom Gained? Assessing Relationships between Adversity, Personality and Well-Being Among An Emerging Adulthood Sample. Journal of youth and adolescence.

Jayawickreme, E., \& Zachry, C. E. (2018). Positive personality change following adversity. In V. Zeigler-Hill \& T. K. Shackelford (Eds.), The SAGE handbook of personality and individual differences (pp. 450-464). SAGE.

Jung, T., \& Wickrama, K. A. S. (2007). An Introduction to Latent Class Growth Analysis and 
Growth Mixture Modeling. Social and Personality Psychology Compass, 2(1), 302-317.

Kelly, J. B. (1989). Mediated and adversarial divorce: Respondents' perceptions of their processes and outcomes. Mediation $Q ., 71$.

Lam, W. W., Bonanno, G. A., Mancini, A. D., Ho, S., Chan, M., Hung, W. K., Or, A., \& Fielding, R. (2010). Trajectories of psychological distress among Chinese women diagnosed with breast cancer. Psycho - Oncology, 19(10), 1044-1051.

Lamade, R. V., Jayawickreme, E., Blackie, L. E. R., \& McGrath, R. E. (2019). Are sequential sample designs useful for examining post-traumatic changes in character strengths? The Journal of Positive Psychology, 1-8. https://doi.org/10.1080/17439760.2019.1610481

Letzring, T. D., Block, J., \& Funder, D. C. (2005). Ego-control and ego-resiliency:

Generalization of self-report scales based on personality descriptions from acquaintances, clinicians, and the self. Journal of Research in Personality, 39(4), 395-422. https://doi.org/10.1016/j.jrp.2004.06.003

Lucas, R. E. (2005). Time does not heal all wounds: A longitudinal study of reaction and adaptation to divorce. Psychological Science, 16(12), 945-950. https://doi.org/10.1111/j.1467-9280.2005.01642.x

Lucas, R. E. (2007). Adaptation and the set-point model of subjective well-being: Does happiness change after major life events? Current Directions in Psychological Science, 16(2), 75-79. https://doi.org/10.1111/j.1467-8721.2007.00479.x

Luhmann, M., Fassbender, I., \& Alcock, M. (2019). A dimensional taxonomy of characteristics of major life events. Manuscript submitted for publication.

Luthar, S. S. (2006). Resilience in development: A synthesis of research across five decades. In D. Cicchetti \& D. J. Cohen (Eds.), Developmental psychopathology (2nd ed., pp. 739- 
795). Wiley.

Mangelsdorf, J., Eid, M., \& Luhmann, M. (2018). Does growth require suffering? A systematic review and meta-analysis on genuine posttraumatic and postecstatic growth.

Psychological bulletin, No Pagination Specified-No Pagination Specified. https://doi.org/10.1037/bul0000173

Martínez-Martí, M. L., \& Ruch, W. (2014). Character strengths and well-being across the life span: data from a representative sample of German-speaking adults living in Switzerland [Original Research]. Frontiers in psychology, 5(1253).

https://doi.org/10.3389/fpsyg.2014.01253

Martínez-Martí, M. L., \& Ruch, W. (2017). Character strengths predict resilience over and above positive affect, self-efficacy, optimism, social support, self-esteem, and life satisfaction. The Journal of Positive Psychology, 12(2), 110-119.

https://doi.org/10.1080/17439760.2016.1163403

Masten, A. S., Best, K. M., \& Garmezy, N. (1990). Resilience and development: Contributions from the study of children who overcome adversity. Development and Psychopathology, 2(4), 425-444. https://doi.org/10.1017/S0954579400005812

McGrath, R. E. (2014). Scale- and item-level factor analyses of the VIA Inventory of Strengths. Assessment, 21(1), 4-14. https://doi.org/10.1177/1073191112450612

McGrath, R. E. (2015). Character strengths in 75 nations: An update. The Journal of Positive Psychology, 10(1), 41-52. https://doi.org/10.1080/17439760.2014.888580

McLean, K. C., \& Syed, M. (2016). Personal, master, and alternative narratives: An integrative framework for understanding identity development in context. Human Development, 58(6), 318-349. https://doi.org/10.1159/000445817 
Muthén, L. K., \& Muthén, B. O. (1998-2012). MPlus User'sGuide. Seventh Edition. Muthén \& Muthén.

Park, N., \& Peterson, C. (2010). Does it matter where we live?: The urban psychology of character strengths. American Psychologist, 65(6), 535-547. https://doi.org/10.1037/a0019621

Park, N., Peterson, C., \& Seligman, M. E. P. (2006). Character strengths in fifty-four nations and the fifty US states. The Journal of Positive Psychology, 1(3), 118-129. https://doi.org/10.1080/17439760600619567

Peterson, C., Park, N., \& Castro, C. A. (2011). Assessment for the U.S. Army Comprehensive Soldier Fitness program: the Global Assessment Tool. American Psychologist, 66(1), 1018. https://doi.org/10.1037/a0021658

Peterson, C., \& Seligman, M. E. P. (2004). Character strengths and virtues: A handbook and classification. Oxford University Press.

Porter, B., Bonanno, G. A., Frasco, M. A., Dursa, E. K., \& Boyko, E. J. (2017). Prospective posttraumatic stress disorder symptom trajectories in active duty and separated military personnel. J Psychiatr Res, 89, 55-64. https://doi.org/10.1016/j.jpsychires.2017.01.016

Proyer, R. T., Gander, F., Wellenzohn, S., \& Ruch, W. (2013). What good are character strengths beyond subjective well-being? The contribution of the good character on self-reported health-oriented behavior, physical fitness, and the subjective health status. The Journal of Positive Psychology, 8(3), 222-232. https://doi.org/10.1080/17439760.2013.777767

Ram, N., \& Grimm, K. J. (2009). Growth mixture modeling: A method for identifying differences in longitudinal change among unobserved groups. International journal of behavioral development, 33(6), 565-576. 
Riolli, L., Savicki, V., \& Cepani, A. (2002). Resilience in the face of catastrophe: Optimism, personality, and coping in the Kosovo crisis. Journal of Applied Social Psychology, 32(8), 1604-1627.

Schueller, S. M., Jayawickreme, E., Blackie, L. E. R., Forgeard, M. J. C., \& Roepke, A. M. (2015). Finding character strengths through loss: An extension of Peterson and Seligman (2003). The Journal of Positive Psychology, 10(1), 53-63. https://doi.org/10.1080/17439760.2014.920405

Schwaba, T., Robins, R. W., Sanghavi, P. H., \& Bleidorn, W. (2019). Optimism development across adulthood and associations with positive and negative life events. Social Psychological and Personality Science.

Shoshani, A., \& Slone, M. (2016). The Resilience Function of Character Strengths in the Face of War and Protracted Conflict. Frontiers in psychology, 6, 2006-2006. https://doi.org/10.3389/fpsyg.2015.02006

Shryack, J., Steger, M. F., Krueger, R. F., \& Kallie, C. S. (2010). The structure of virtue: An empirical investigation of the dimensionality of the virtues in action inventory of strengths. Personality and Individual Differences, 48(6), 714-719. https://doi.org/10.1016/j.paid.2010.01.007

Smith, K. V., \& Ehlers, A. (2020). Cognitive predictors of grief trajectories in the first months of loss: A latent growth mixture model. Journal of consulting and clinical psychology, 88(2), 93-105. https://doi.org/10.1037/ccp0000438

Smith, T. C., Ryan, M. A., Wingard, D. L., Slymen, D. J., Sallis, J. F., \& Kritz-Silverstein, D. (2008). New onset and persistent symptoms of post-traumatic stress disorder self reported after deployment and combat exposures: prospective population based US military cohort 
study. Bmj, 336(7640), 366-371.

Tedeschi, R. G., \& McNally, R. J. (2011). Can we facilitate posttraumatic growth in combat veterans? American Psychologist, 66(1), 19-24. https://doi.org/10.1037/a0021896 (Comprehensive Soldier Fitness)

Tennen, H., \& Affleck, G. (1998). Personality and transformation in the face of adversity. In R. G. Tedeschi, C. Park, \& L. G. Calhoun (Eds.), Posttraumatic growth: Positive changes in the aftermath of crisis (pp. 65-98). Lawrence Erlbaum Associates Publishers.

Tennen, H., \& Affleck, G. (2009). Assessing positive life change: In search of meticulous methods. In C. R. Snyder \& S. J. Lopez (Eds.), Handbook of positice psychology (pp. 584-597). Oxford University Press.

van de Schoot, R., Sijbrandij, M., Winter, S. D., Depaoli, S., \& Vermunt, J. K. (2017). The GRoLTS-Checklist: Guidelines for Reporting on Latent Trajectory Studies. Structural Equation Modeling: A Multidisciplinary Journal, 24(3), 451-467. https://doi.org/10.1080/10705511.2016.1247646

Vanhove, A. J., Harms, P. D., \& DeSimone, J. A. (2016). The Abbreviated Character Strengths Test (ACST): A preliminary assessment of test validity. Journal of personality assessment, 98(5), 536-544. https://doi.org/10.1080/00223891.2016.1148044

Vie, L. L., Griffith, K., Scheier, L., Lester, P., \& Seligman, M. (2013). The Person-Event Data Environment: Leveraging big data for studies of psychological strengths in soldiers [Technology Report]. Frontiers in psychology, 4(934). https://doi.org/10.3389/fpsyg.2013.00934

Vie, L. L., Scheier, L. M., Lester, P. B., Ho, T. E., Labarthe, D. R., \& Seligman, M. E. (2015). The U.S. Army Person-Event Data Environment: A military-civilian big data enterprise. 
Big Data, 3(2), 67-79. https://doi.org/10.1089/big.2014.0055

Vie, L. L., Scheier, L. M., Lester, P. B., \& Seligman, M. E. P. (2016). Initial validation of the U.S. Army Global Assessment Tool. Military Psychology, 28(6), 468-487. https://doi.org/10.1037/mil0000141

Yanez, B. R., Stanton, A. L., Hoyt, M. A., Tennen, H., \& Lechner, S. (2011). Understanding perceptions of benefit following adversity: how do distinct assessments of growth relate to coping and adjustment to stressful events? Journal of Social and Clinical Psychology, 30(7), 699-721. 
Table 1. Model Fit and Classification Statistics

\begin{tabular}{|c|c|c|c|c|c|}
\hline AIC & Intellect & $\begin{array}{l}\text { Civic } \\
\text { Strengths }\end{array}$ & Warmth & Temperance & Total \\
\hline 1 Class & 5004824.770 & 4905565.192 & 4948786.221 & 4993896.097 & 4883665.371 \\
\hline 2 Class & 4943664.716 & 4813453.653 & 4841239.202 & 4935664.888 & 4813340.098 \\
\hline BIC & Intellect & $\begin{array}{l}\text { Civic } \\
\text { Strengths }\end{array}$ & Warmth & Temperance & Total \\
\hline 1 Class & 5005040.359 & 4905780.782 & 4949001.810 & 4994111.687 & 4883880.960 \\
\hline 2 Class & 4944034.298 & 4813823.235 & 4841608.784 & 4936034.470 & 4813709.680 \\
\hline BLRT $p$ value & Intellect & $\begin{array}{l}\text { Civic } \\
\text { Strengths }\end{array}$ & Warmth & Temperance & Total \\
\hline 1 Class & NA & NA & $\mathrm{NA}$ & NA & NA \\
\hline 2 Class & $<.0001$ & $<.0001$ & $<.0001$ & $<.0001$ & $<.0001$ \\
\hline Entropy & Intellect & $\begin{array}{l}\text { Civic } \\
\text { Strengths }\end{array}$ & Warmth & Temperance & Total \\
\hline 1 Class & $\mathrm{NA}$ & $\mathrm{NA}$ & $\mathrm{NA}$ & NA & $\mathrm{NA}$ \\
\hline 2 Class & 0.433 & 0.500 & 0.526 & 0.440 & 0.461 \\
\hline
\end{tabular}


Table 2. Class membership and patterns across the deployment cycle

\begin{tabular}{|c|c|c|c|c|c|c|c|c|c|c|c|}
\hline & & \multirow{2}{*}{$\begin{array}{c}\% \text { in } \\
\text { Class }\end{array}$} & \multirow{2}{*}{$\begin{array}{c}\text { Mean } \\
\text { Predicted } \\
\text { Probability }\end{array}$} & \multicolumn{2}{|c|}{ Pre-Deployment } & \multicolumn{2}{|c|}{ Post-Deployment 1} & \multicolumn{2}{|c|}{ Post-Deployment 2} & \multicolumn{2}{|c|}{ Post-Deployment 3} \\
\hline & & & & Estimate & $95 \% \mathrm{CI}$ & Estimate & $95 \% \mathrm{CI}$ & Estimate & $95 \% \mathrm{CI}$ & Estimate & $95 \% \mathrm{CI}$ \\
\hline Resilient & Total & 63.47 & 0.83 & 4.38 & $4.37-4.39$ & 4.39 & $4.28-4.41$ & 4.41 & $4.37-4.45$ & 4.44 & $4.38-4.50$ \\
\hline "Stable & Intellect & 58.50 & 0.81 & 4.32 & $4.31-4.33$ & 4.33 & $4.22-4.38$ & 4.36 & $4.31-4.41$ & 4.39 & $4.31-4.47$ \\
\hline High” & Civic Strengths & 59.45 & 0.83 & 4.60 & $4.59-4.61$ & 4.61 & $4.47-4.63$ & 4.59 & $4.52-4.66$ & 4.60 & $4.52-4.68$ \\
\hline \multirow[t]{2}{*}{ Class } & Warmth & 60.19 & 0.84 & 4.60 & $4.59-4.60$ & 4.60 & $4.50-4.64$ & 4.58 & $4.57-4.60$ & 4.64 & $4.57-4.71$ \\
\hline & Temperance & 52.29 & 0.79 & 4.44 & $4.44-4.45$ & 4.44 & $4.36-4.49$ & 4.48 & $4.42-4.54$ & 4.49 & $4.42-4.56$ \\
\hline Declining & Total & 36.53 & 0.86 & 3.66 & $3.65-3.68$ & 3.43 & $3.27-3.59$ & 3.46 & $3.35-3.56$ & 3.47 & $3.31-3.63$ \\
\hline "Persistent & Intellect & 41.50 & 0.86 & 3.51 & $3.49-3.53$ & 3.25 & $3.07-3.42$ & 3.34 & $3.23-3.45$ & 3.39 & $3.22-3.57$ \\
\hline Low” & Civic Strengths & 40.55 & 0.89 & 3.79 & $3.77-3.80$ & 3.59 & $3.41-3.76$ & 3.66 & $2.50-3.81$ & 3.67 & $2.49-3.84$ \\
\hline \multirow[t]{2}{*}{ Class } & Warmth & 39.81 & 0.90 & 3.79 & $3.77-3.80$ & 3.55 & $3.31-3.80$ & 3.55 & $3.51-3.60$ & 3.54 & $3.30-3.79$ \\
\hline & Temperance & 47.71 & 0.87 & 3.59 & $3.57-3.61$ & 3.42 & $3.24-3.60$ & 3.51 & $2.36-3.67$ & 3.53 & 3.34-4.71 \\
\hline
\end{tabular}

Note. $\mathrm{N}=212,386$. Full Information Maximum Likelihood was used to estimate means. 
Figure 1. GAT completion rates in this study

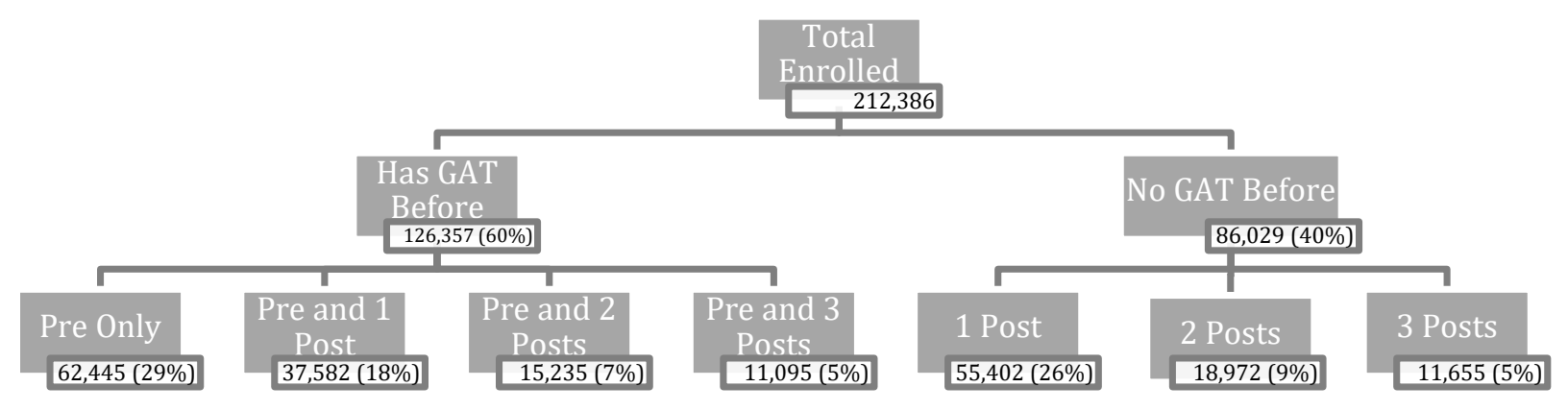


Figure 2. Character change across the deployment cycle

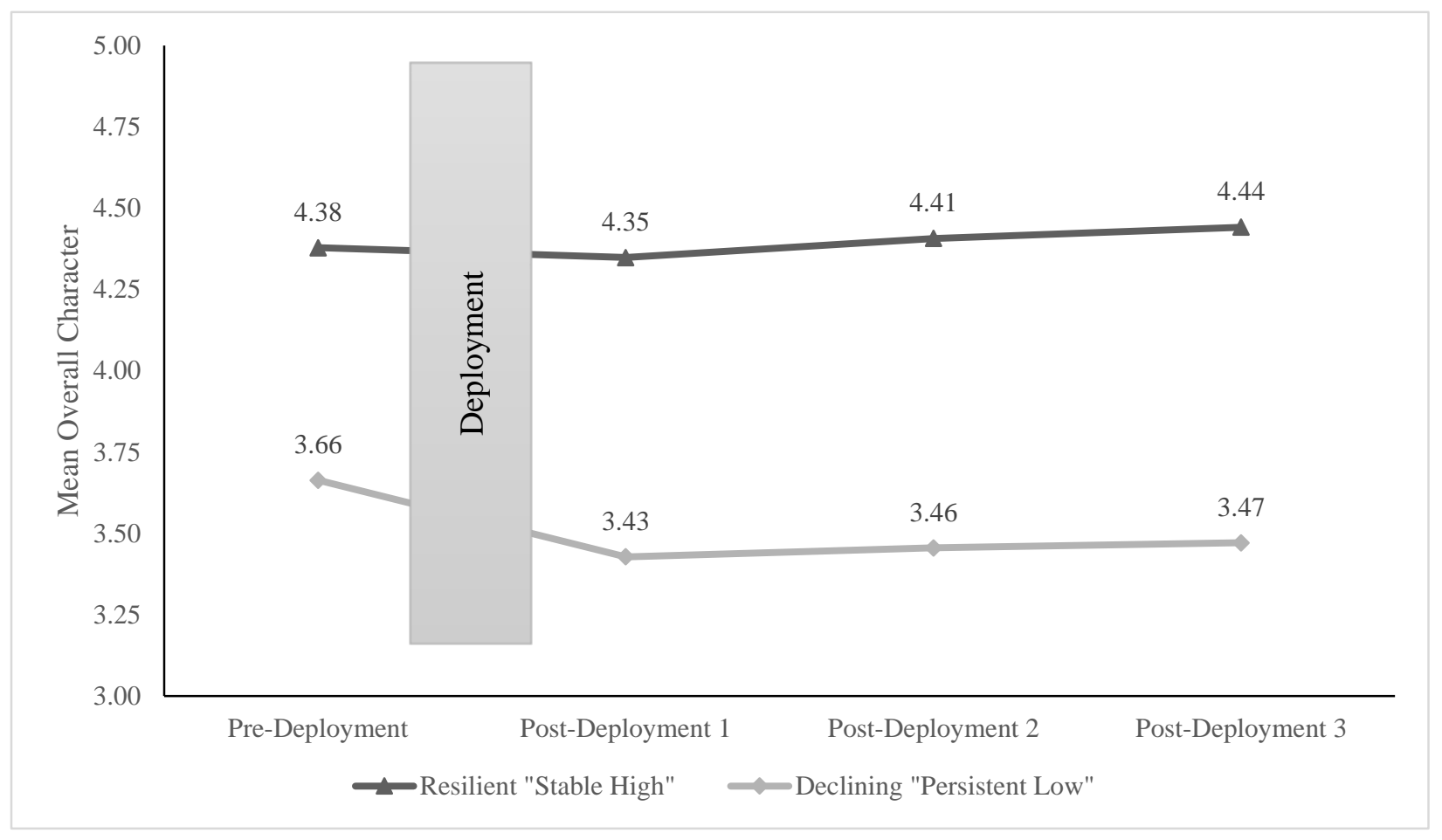

